\title{
30 Years Trend of Competitive Balance in Turkish Football Super League
}

\author{
Tuğbay Inan \\ Correspondence: Tuğbay Inan, Spor Bilimleri ve Teknolojisi Yuksekokulu Dokuzeylul Universitesi Saglik Yerleskesi, \\ 35340 Inciralti, Izmir, Turkey.
}

Received: December 5, 2017

Accepted: December 14, 2017

Online Published: December 21, 2017

doi:10.11114/jets.v6i1.2844

URL: https://doi.org/10.11114/jets.v6i1.2844

\begin{abstract}
We must point out that the results of football games affect the competitive balance degree. In other words, the calculations we made in the score table at the end of the season give us a degree of competitive balance. The degree on which the concept of competitiveness is based is cited as competitive balance in football. Sports economics can be defined as the degree to which overall league attendances are raised by such measures as media effect, home advantage, income sharing, all of which aim to strengthen the competitive balance. The aim of this study was to gauge the competitive balance in Turkish football league. Using long term competitive balance analysis, some of the matters encountered and possible precautions to be taken were approached in a way that can discuss the mentioned subjects throughout the 1987-2017 seasons in Turkish Football Super League (TSL). The present study examined the way that competitive balance level followed in the history of super league (30 years). For this purpose, C5 Competitive Balance Index (C5CBI) and a Herfindahl index of competitive balance (HICB) were benefited. Finally, competitive balance factor was observed to have occured time to time; however, when looked in terms of total, a view apart from competitive balance can be clearly seen.
\end{abstract}

Keywords: Competitive Balance, Turkish football, C5 competitive balance index, Herfindahl-Hirschman

\section{Introduction}

Expanding globalization has brought about some concomitant developments and innovations in the field of sports as in every field. In today's world, sports, sports organizations and sports events have started to be recognized as a product. Expansion and emergence of sports marketing, sponsorship and accompanying economics, and the increasing number of the studies conducted in the mentioned fields may be regarded as a positive enhancement for sports as a whole (Inan, 2011). The relationship between sports and economy can be traced back to the first antique Olympic games at the end of which the athletes were compensated with either goods or species (Andreff, 2008).

In the last two decades, football has evolved into a multibillion dollar industry and has been witnessed to generate huge revenues for private individuals and clubs in addition to national and international organisations. How these revenues are generated can be listed within the scope of broadcasting rights, sponsorship agreements, merchandise and ticket sales. Resources are allocated based on the performances at domestic and international levels (Halıcıoğlu, 2009).

They can be regarded as unequalled in essence when compared to traditional consumption products. When the latter is bought, should it not satisfy the expectations of the buyer or should any kind of problem arise after buying, producers guarantee that they will take the already sold product back by refunding the cost charged to the buyer or by exchanging it with another or at least by repairing it. However, a sports event not meeting or satisfying the consumers' expectation has no chance to undergo these procedures peculiar to corporal satisfactory policies involving all these procedures. Furthermore, you have no chance to keep it in order to use it later. All the results of the matches will remain unchanged (Inan, 2011).

Besides, the likelihood of an unexpected score during any sports event increases the excitement and expectations of the spectators, thus helping sports product to be alluring and attractive. Not being able to predict the results or scores to be seen during an event is one of the most important characteristics of sports, which distinguishes sport from traditional consumption products.

Sport leagues are required to be equipped with a significant competition balance so that they can continue their existence. Particularly, the income ratio obtained from the supporters can be elevated through the high-competitive leagues in which the match results are uncertain 
Today, the sport branch involving a name and content that are in everybody's lips by facing us with bigger and increasingly advanced organizations is football. Thanks to the ceaseless developments, as encountered in all parts of the world, have not only triggered a structural transformation process but also led it to become an industry needed to be managed according to profit and utility maximization principles, and with strategic and financial approaches.

That there is a exciting uncertainty over which team will become the champion at the end of the season in a football league is what attracts fans and spectators. In this sense, therefore, a certain degree of competitive balance in football leagues is a must to keep the interest in the league alive.

In an attempt to maximize the ambiguity of results in competitions, the organizations of football events try to create some rules and limitations. In a league, if some teams are superior over others with the more power and chances they have, the might mean that the league will lose its appeal for being predictable. On the other hand, having too much competitive balance causes inability to predict the outcome of the match at all. Normally in a what we call as a balanced league, every team has equal rate of chance to win; therefore, of all these teams, any team can win the championship of end of league.

In a research conducted by Michie and Oughton (2004), it was also supported that deficiency of competitive balance means decreased number of spectators and that the league runs the risk of losing supporters in the long run. Unbalanced football leagues also result in various risks, such as failure, or threat of failure.

In general economics, firms try to gain dominance over others and outperform their competitors. However, when it comes to sports, we need to talk about specific economic characteristics as this kind of competitive behaviour is absent in this field. Teams do aim to win but not all the time.

In the event that only one team survives, no games could be played and so the sports branch ceases to exist. The product in sports is a result of two firms, and a certain level of competitive balance can be considered to be necessary to hold people's interest (Janssens \& Késenne, 1987).

One of the reasons for interest in a particular soccer game, or in any sports contest, is the uncertainty of the outcome of that. Big teams tend to win their games but sometimes they are surprisingly beaten by an inferior team. Many of soccer fans would recall stories about a leader team in a league which lost unexpectedly against a team beating it despite being in the bottom of the league. In fact, soccer results are quite random in the sense that only a few goals are scored during each game; and therefore, chance may be a quite influential factor in determining the outcome of a game (Koning, 1999).

The issue of Competitive Balance is a central issue in the literature available on the economic gains of professional sports. The basic idea and recommendation would be that the managers of professional sports leagues should maintain a certain level of competitive balance in their league, if they are aiming it to remain appealing (Rottenberg, 1956; El Hodiri \& Quirk, 1971) .

In his seminal article dated 1956, Rottenberg, on the other hand, anticipated the relevance of the Coase Theorem (Coase, 1960) in perceiving the talent distribution across teams, and put forward that the profit motive would limit the accumulation of player talent on any single team. El Hodiri and Quirk (1971) revealed in the first formal modelling of a professional sport league that individual team profit maximization does not correlate with equal playing strengths among the teams except in the special case of identical team revenue functions. Fort and Quirk (1995) bring the problem of competitive balance in sports leagues into focus and evaluate the extent to which different mechanisms create greater balance (Zimbalist, 2002).

On the other hand, the studies focusing on competition during a single season measured it as the standard deviation of winning percentages (La Croix \& Kawaura, 1999; Butler, 1995); the range of winning percentages (La Croix \& Kawaura, 1999); and the variance of winning percentages, games-behind dispersion, and number of teams within five games of first place at the end of season (Balfour \& Porter, 1991). In an attempt to test the presence of dynasties, competitiveness has been measured in time using Herfindahl-Hirschman Indices of pennant winners or last-place finishes (La Croix \& Kawaura, 1999); the correlation of winning percentages over time (Balfour \& Porter, 1991; Butler, 1995); and the change in mean winning percentages across regime changes (La Croix \& Kawaura, 1999).

Seasonal uncertainty is mostly measured rather roughly, such as the standard deviation in the winning percentages over the season, or a variable standing for the average number of clubs competing for the championship. Jennett (1984) utilized a more sophisticated evaluation by calculating the championship significance of matches as the reciprocal of the number of matches required to win the championship (calculated ex post). He considers its significance for both the home and the away team. Again, it means that even if the performance of a given team outweighs the other, it is hard to foresee the result in a seriously contested match.

Long-run domination has been less frequently measured than the above mentioned ones. Exceptional ones are seen in the studies of Humphreys (2002) and Buzzachi et al. (2003). The former notes that variations in winning percentages 
over a number of seasons can be measured in two different ways one of which is to do it within season variations in winning percentages of different teams, while the other is within season variation in winning percentages across all teams. These are then combined into a competitive balance ratio proving statistically significant. Buzzachi et al. (2003) consider the cumulative frequency of teams entering the top $\mathrm{k}$ ranks of a league (ordered by win percentages), but expansion of leagues in North America and changes in the composition of teams through promotion and relegation in Europe confuse the picture (Sloane, 2006).

Numerous researchers present useful reviews on the different measures of competitive balance, which range from simple measures of dispersion, such as standard deviations of winning percentages around league means, team means over time or at a point in time, modifications of Gini indices to C5 and the deviations of the Herfindahl-Hirschman Index.

\section{Method}

It has been expressed that the empirical studies carried out on competitive balance follow two directions, the first one of which is the competitive balance itself. In these analyses, the change of the competitive balance in the course of time is investigated and on the other hand, the second one investigates the influences of the competitive balance on spectators. Both analyses are necessary for a well established grasp of the relationship among the structure of a league, competition level and spectators' benefit (Gürel, 2007).

It is also seen that various methods are employed to analyze a competitive balance in literature. Some of the methods employed in the fields of economics, statistics and other fields have been incorporated into the analyses of competitive balance. The percentages of wins, calculations done with lorenz curve, the five clubs concentration ratio (C5) and Herfindahl-Hirschman index are the methods intensely applied.

\subsection{The C5 Five Clubs Concentration Ratio and C5CIB Index of Competitive Balance}

Competitive balance can be measured in a number of ways. The concentration ratio measures of the competitive balance of a sports league are based on an assessment of the concentration of a subset of the teams in the league relating to a comparative statistic.

Normally, C5 concentration ratio measures the extent to which an industry is predominated by the 5 large firms in a standard industry. When applied to sport leagues such as football, the 5 clubs measure the ratio imbalance between the top 5 clubs and the rest of the league.

C5 has a value between zero and one under the assumption that there is no market entry or exit barrier in a standard competitive industry. A value of " 0 " points to the existence of an infinite number of firms and perfect competition, whereas a value of "1" illustrates the status of a full monopoly. In other words, an increase in C5 may be an indicative of a decline in the competitive balance and the dominance ratio of the top five clubs in the league. The number of clubs is fixed in football and it is not viable for the top five clubs to sum up all the points due to the scoring system. As these teams will play with each other as well, there will be surely a loss of point. Considering the restrictions, the index will have the following value in such a case;

$$
\frac{5}{N}<C 5<\frac{M}{(M+T)}
$$

$\mathrm{N}$ stands for the number of the clubs and $\mathrm{M}$ for the maximum point that the top five clubs can have, while $\mathrm{T}$ shows the absolute minimum point which the rest of the clubs can collect in matches they play with each other. Because the number of clubs is fixed, the changes in $\mathrm{C} 5$ will reflect the variations in the inequality and the variations in dominance of the top five clubs. However, the structure of the league may change and the number of the teams and the league size may show changes. In order to be able to include the effect of the changes in the size of the league in the calculation, C5 ratio should be compared to the ideal status with perfect competitive balance.

$$
\mathrm{C} 5 \mathrm{ICB}=\left[\frac{\mathrm{C} 5}{5 / \mathrm{n}}\right] * 100
$$

In an ideal football league, the value of the $\mathrm{C} 5$ Index of Competitive Balance is recognized as 100. This ratio increases as the competitiveness decreases. A rise in this ratio over 100 indicates the football league is separating from the accepted ideal competitive balance level (Michie \& Oughton, 2004). 


\subsection{HHI-Herfindahl Hirchman Index and HICB-Herfindahl Index of Competitive Balance}

Another index utilized is The Herfindahl-Hirchman index (HHI) which is often employed to characterize the distribution of a variable of interest by measuring its extent of concentration across units, such as firms, teams or households.

The five club concentration ratio examines the inequalities or imbalances present between the top 5 clubs and the bottom rest (Michie \& Oughton, 2004), while The Herfindahl Hirschman index (HHI) looks at the inequalities among all the firms in an industry. When applied to football leagues, it captures inequalities between all the clubs that form a football league. A key difference between the application of the HHI to a sports league and to an industry is the fact that the league structure imposes a restriction on the range of the measure which also depends on the number of teams in the league.

The index relies on a calculation of the league share of every club's for end of season in a football industry league context. Using each club's season share as its weight, the share of points is then summed into a weighted average index for the football industry

HHI= Herfindahl Hirchman index

$$
H H I=\sum_{i=1}^{N} S_{i}^{2}
$$

$\mathrm{N}=$ The number of clubs in the league

$S i=$ Club i's share of points in a season,

As in the five-club concentration ratio, the H-index is a function of the number of clubs that make up the league and the inequalities between those clubs in terms of winning power. The $\mathrm{H}$ index reflects the degree of competitive balance between teams. Any increase in the index points out an increase in the inequality and therefore a decline in competitive balance. In a standard industry context, the Herfindahl index lies between 0 (with an infinite number of firms) and 1 (pure monopoly); however when it is applied to football, restrictions on the number of teams in a league and constraints imposed by the points scoring system mean the index lies well within this range (Michie \& Oughton, 2004) .

In a league of 18 teams, the lower limit of the H-index would be 0.055 (the value achieved in a perfectly balanced league), while the upper limit would be 0.076 (the value attained in a perfectly unbalanced league with the most unequal distribution of attainable points).

\subsection{The Herfindahl Index of Competitive Balance (HICB)}

As in the $\mathrm{C} 5$ ratio, the Herfindahl index is sensitive to the changes in the number of teams. This can be corrected by dividing the index with the value of $\mathrm{H}$ to be attained in a perfectly balanced league to obtain the $\mathrm{H}$ Index of Competitive Balance (HICB) as shown below:

$$
H I C B=\left[\frac{H}{1 / N}\right] * 100
$$

$\mathrm{H}=$ Herfindahl-Hirchman index

$\mathrm{N}=$ The number of clubs in the league

In a perfectly balanced league of any size, the Herfindahl index of competitive balance would take the value of 100 . A decline in competitive balance is reflected by an increase in the index.

\section{Results}

Competitive balance has become a great interest among sports economists and has encouraged significant amount of research in the area. Much of this literature is focused on professional sports with particular attention paid to football. It is commonly claimed that measures to promote competitive balance in sports leagues will elevate attendances. Thus, greater competitive balance should lead to greater demand while other things are maintained equally.

The initial method to be employed in the study is the Club Concentration Ratio and C5 index of competitive balance. Because the top five teams cannot win all the points due to the nature of football and basketball, the value of the index varying between 0 and 1 is adjusted. The value of 0 which stands for the lower limit of the index is redistributed as $5 / \mathrm{N}$ ( $\mathrm{N}$ for the number of the teams) and the value of 1 standing for the higher limit is rearranged as $\mathrm{M} / \mathrm{M}+\mathrm{T}(\mathrm{M}$ for the sum of all points that can be won by the 5 clubs, $T$ for the minimum points that the other teams can attain). As seen in the Table 1 the lower limit of the club concentration ratio will be accepted as 0.31 and higher limit as 0.64 in the years when there are 16 teams in the league; and the lower limit is taken as 0.27 and higher limit as 0.60 when there are 18 teams. 
Table 1. The lower and upper limit of C5 Ratio

\begin{tabular}{lll}
\hline Number of Teams in the League & Lower limit & Higher limit \\
\hline 16 & 0,31 & 0,64 \\
18 & 0,27 & 0,60 \\
19 & 0,26 & 0,57 \\
20 & 0,25 & 0,55 \\
\hline
\end{tabular}

109 active professional football clubs which compete in 4 professional leagues have been registered by Turkish Football Federation (TFF, 2017). This number of teams has been volatile in TSL through the years. For instance, TSL was composed of 20 teams in 1987-1988 season, 19 teams in 1988-1989 season, 18 teams in season 1989-1990, 16 teams in seasons 1990-1994, and then 18 teams in seasons 1994-2017. Furthermore, calculations have been carried out based on the 18.360 football games in the last three decades. According to the data obtained from the study, considering the competitive balance, there is an undulating and irregular situation in TSL. From this study, it was found that when the mean concentration rates of clubs and C5 was examined, it became obvious that the share of first five clubs in TSL was $40 \%$.

It was also detected that when low concentration rates of clubs and C5 were examined, it was seen that the share of first five clubs in the season 1987-1988, TSL was 33\%, and then, when the same was done for high concentration rates in the season 1992-1993, TSL was seen to be $47 \%$. TSL was made up of 20 teams in the season 1987-1988, whereas 16 teams in season 1992-1993.

C5 ratio should be compared to the ideal situation with perfect competitive balance to include the effect of the changes on the size of the league. That's why; $\mathrm{C} 5$ Index of Competitive Balance (C5CBI) has been calculated. The value of the competitive balance index should be 100 in a league so that it can be recognized as having a perfect competitive balance. Any increase in the competitive balance level would reduce this ratio. An upward trend in this ratio over 100 is an indicative of the fact that the league moves to more unbalanced situation

C5CIB for Turkish football super leagues was provided in Figure 1. The mean C5ICB was seen to be 146 between the seasons of 1987-2017. It was found between the 1987-2017 seasons that the season that moves away from the competition the most is the 1995-1996 season with the rate of 158; whereas, the season that gets close to the competition at most is the 2006-2017 season with the rate of 129 (Fig. 1), which is so far from the competition balance.

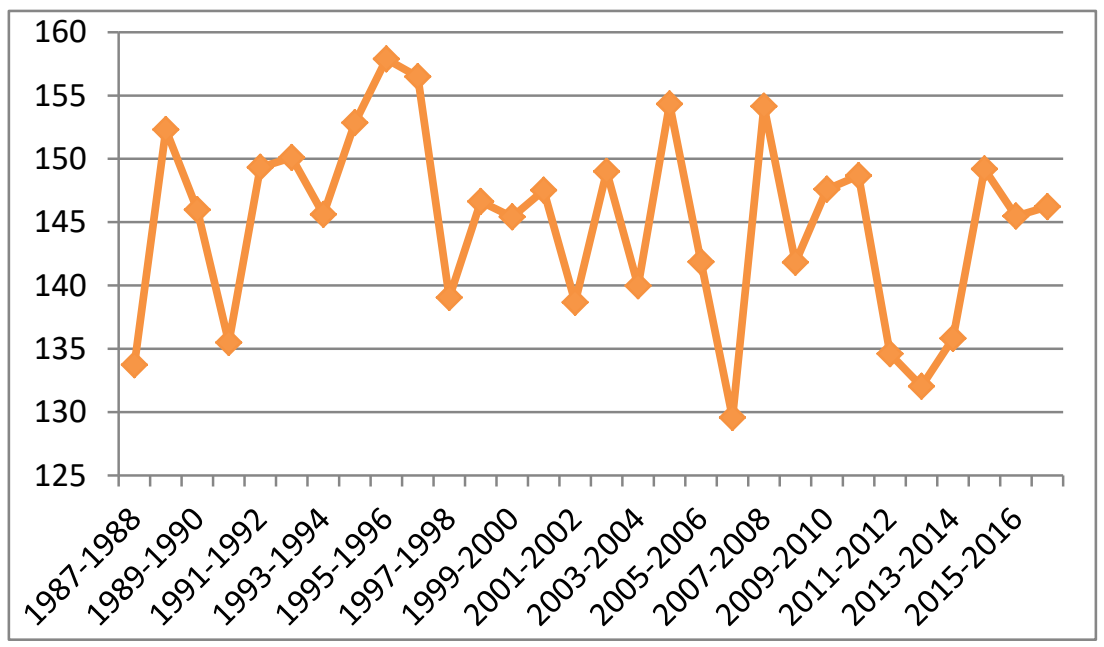

Figure 1. The Five-Club Concentration Ratio Index of Competitive Balance (C5CIB)

It was found in this study that the mean Herfindahl- Hirschman index (HHI) was seen to be 625. On the other hand, the mean HICB was seen to be 110 between the seasons of 1987-2017. It was determined for the 1987-2017 seasons that the season that diverges from the competition the most in terms of HICB is the 1996-1997 season with the rate of 115; whereas, the season that gets close to the competition at most is the 2006-2007 season with a rate of 105 (Fig. 2). 


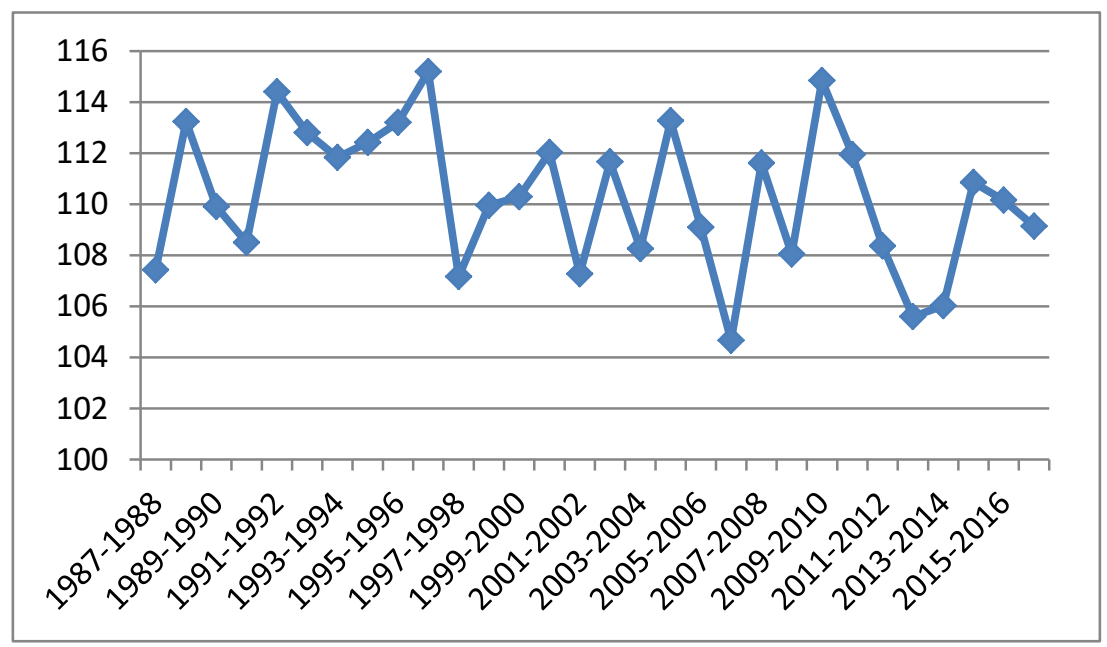

Figure 2. The Herfindahl Index of Competitive Balance (HICB)

Looking at Figure 1 and Figure 2 in terms of C5ICB and HICB, it can be concluded that they presented a wavy path that approaches to the competition and diverged from the competition within the years.

\section{Discussion}

If the football seasons in Turkey are examined, we observe that the Turkish football moved to 3-point system in 1987. In the case of impacts of the point system on the degree of competition balance in football; TSL had a 3 point system in the seasons 1987-2017. 4 teams became champions through the seasons 1987-2017 in TSL as follows; Galatasaray 13 times, Fenerbahçe 8 times, Beşiktaş 8 times and Bursaspor 1 time.

On the other hand, broadcasting rights model was rearranged in line with the decision taken in 2005 by Turkish Football Federation. According to the new broadcasting rights model, football clubs that got more from the shares previously have begun to share their assets with other clubs listed in TSL. Before the rearrangement of the broadcasting rights model, mean C5ICB value was 147 through the seasons 1987-2005; however, after the modification, this average was identified as 142 during the seasons 2005-2017. In addition, when the HICB average values were calculated for the same seasons, the average was identified as 111 during the seasons 1987-2005, and as 109 during the seasons 2005-2017.

According to the mean values, we can say that due to the new broadcasting rights model, small-budget clubs in TSL can get more funding in the event that they get more points during the season. This situation may also lead to an increase in competition.

Should the competition continue to increase in the years ahead, more spectators will be coming to the matches, football clubs will be gaining new fans, and based on these reasons, they will start to sign for more valuable sponsorship and advertising agreements, thus increasing their commercial revenues. Also, it can be concluded that Clubs will be increasing their competitiveness through rebroadcast incomes as well as their commercial revenues.

You may also consider the following issues:

- Clubs, which are increasingly getting strong fiscally, can ensure more spectators to come to the matches by making investments in new stadiums.

- Increasing the competition in the league can make football clubs more valuable in TSL.

- Competitions of the clubs can provide financial transparency in particular.

- In addition, increasing competition can enhance the watching ratio of the TSL matches on TV and ensure new subscribers for the broadcasters. This situation will increase the broadcasters' profitability; as a consequence, more funding will be diverted to football clubs in the following years.

As a result, clubs, which have strong competitive ability, can also contribute to the growth of football industry in Turkey.

\section{References}

Andreff, W. (2008). Globalization of the Sports Economy, Rivista di Diritto ed Economia dello Sport, 4(3), 13-32.

Balfour, A., \& Porter, P. K. (1991). The reserve clause and professional sports: Legality and effect on competitive balance, Labor Law Journal, 42(1), 8-18. 
Butler, M. R. (1995). Competitive Balance in Major League Baseball, The American Economist, 39(2), 46-52.

Buzzachi, L., Szymanski, S., \& Valletti, T. M. (2003). Equality of Opportunity and Equality of Outcome: Open Leagues, Closed Leagues and Competitive Balance, Journal of Industry, Competition and Trade, 3(3), 167-186.

Coase, R. (1960). The problem of social cost, Journal of Law and Economics, 3, 1-44.

Fort, R., \& Quirk, J. (1995). Cross-Subsidization Incentives and Outcomes in Professional Team Sports Leagues, Journal of Economic Literature, 33(3), 1265-1299.

Gürel, S. P. (2007). Competitive Balance in Football Leagues and an Analysis of Competitive Balance for The Turkish 1. Football League. (Master's thesis), Pamukkale University, Denizli, Turkey.

Halıcıoğlu, F. (2009). Research on the prediction of the likely winners of the euro 2008 football tournament, Journal of Quantitative Analysis in Sports, 5(39), 1-15.

Humphreys, B.R. (2002). Alternative Measures of Competitive Balance in Sports Leagues, Journal of Sports Economics, 3(2), 133-148.

Inan, T., \& Kaya, M. (2011). Competitive Balance in Turkish Soccer, Ekonomika a Management, 5(2), 51-59.

Janssens, P., \&Késenne, S. (1987). Belgian Soccer Attendances, Tijdschrift voor Economie en Management, 32(3), 305-315.

Jennett, N. (1984). Attendances, Uncertainty of Outcome and Policy in the Scottish Football League, Scottish Journal of Political Economy, 31(2), 176-198.

Koning, R. H. (1999). The Competitive Balance in Dutch Soccer (Research Report 99B04), University of Groningen, Research Institute Systems Organisations and Management.

La Croix, S., \& Kawara, A. (1999). Rule Changes and Competitive Balance in Japanese Professional Baseball, Economic Inquiry, 37(2), 353-368.

Michie, J., \& Oughton, C. (2004). Competitive Balance in Football: Trends and Effects (Research Paper No. 2), University of London, Football Governance Research Centre.

Quirk, J., \& El Hodiri, M. (1974). The Economic Theory of A Professional Sports League, in Noll, R. (eds), Washington DC: Brookings Institution Press, 33-80.

Rottenberg, S. (1956). The Baseball Player's Labor Market, Journal of Political Economy, 64(3), 242-258.

Sloane, P. J. (2006). Rottenberg and the Economics of Sport After 50 Years (Research Paper No. 2175), University of Wales, Swansea, The Institute for the Study of Labor.

Turkish Football Federation. (2017). Official Web Site Info Bank. http://www.tff.org/Default.aspx?pageID=520

Zimbalist, A. S. (2002). Competitive Balance In Sports Leagues: An Introduction, Journal of Sports Economics, 3(2), 111-121.

\section{Copyrights}

Copyright for this article is retained by the author(s), with first publication rights granted to the journal.

This is an open-access article distributed under the terms and conditions of the Creative Commons Attribution license which permits unrestricted use, distribution, and reproduction in any medium, provided the original work is properly cited. 